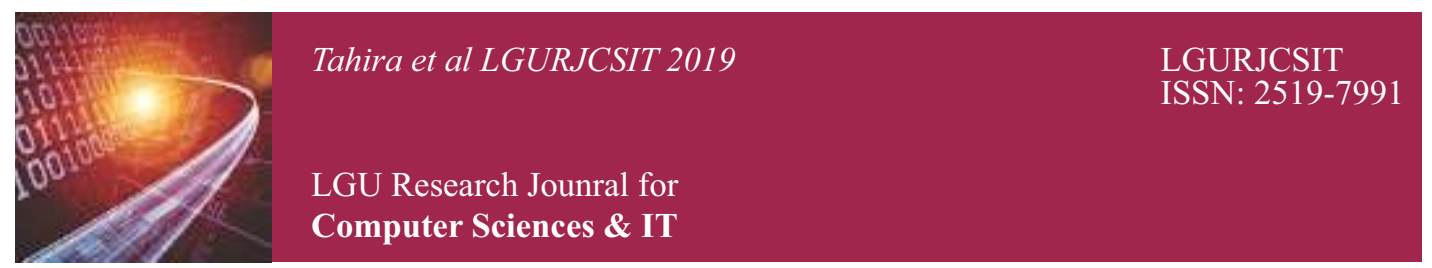

Vol. 3 Issue 1, January - March 2019

\title{
A Technical Survey of an Automated Driving System
}

${ }^{1}$ Khadija Tahira, ${ }^{2}$ Hafsa Khalid

${ }^{1}$ Lecturer in CS\&IT department, Minhaj University Lahore, Township Lahore, Pakistan.

${ }^{2}$ Lecturer in CS\&IT department Minhaj University Lahore

${ }^{1}$ khadija.csit@mul.edu.pk ${ }^{2}$ Hafsa.csit@mul.edu.pk

\section{Abstract:}

This paper tells the development of automated vehicles which explore the functions of driving at different levels, its implementation and infrastructure. Automated driving system (ADS) detects collision, performs some task to avoid it, focuses on Driver interaction with the system in the terms that can be controllable in rush being driven by the driver, which cause accidents, because safety, comfort ,time saver\& destination are the most vital aspects of automation. Automated driving plays an important role in society but at the same time it also has some flaws which needs to be overcome in future. With some analytical surveys of published research papers of this era we will try to provide a clear description of automated driving system and how it can work effectively and efficiently.

Keywords: $\quad$ Automated system, collision detection \& avoidance, automated levels, operational model of automation, infrastructure of automation

\section{INTRODUCTION}

The future is mysterious no one knows what the things will going to happen in future but from the past experience and proper planning we can predict what will be the future condition and what the things will happen. In this modern era vehicles are attentive to be automated to gives relaxation to human driver. In this field numerous aspects have been considered which makes a vehicle automated. [11]. For this many of the researchers consider that how automated driving system will effect in future,with proper planning of roads, parking issues either it is supported by public or rejected by them. Basically purpose of automated driving is to deliver the [5] role of driver to the machine vehicle. Automated driving is an expansion of advance driver system with environmental sensing. Automated system explores three phases of the self-driving car rebellion: 1 st one is the historical viewpoint with a concentration on perception for autonomous vehicles 2 nd one is how government policy will influence on selfdriving cars technically and commercially and the last thing is how cloud-based infrastructure plays a role in the future. [14]. the agenda of this paper is to finish crashes improve safety, remove congestion, collision detection and avoidance [5] and remove emission for the sake of health. The biggest challenge of automated system is sensory issue that need to be solved in future. Taking intelligent decision in traffic is also an issue for automated driving system.

\section{LITERATURE REVIEW}

In 1990s many of the private institutions in Europe and Japan focus on to bring an idea of automated driving system, the emphasis of the research is to provide safety in automation, and the very well research were performed with the sensors but there were lots of issues that is not solved like safety and completely sensory issue. [8] A demonstration in 1926 were showed a full vehicle is controlled by radio waves. In 1950 self-driving cars are discussed throughout the period. [8] In 1984 Carnegie Mellon's Navlab early $21^{\text {st }}$ century start the struggle of development of automated system and the DARPA wins the challenge of driverless vehicle which drives 150 mile route, and 5 more vehicle 
accomplished this challenge and till 2000s automated system continued enough growth, In $20072^{\text {nd }}$ grand challenge requires 60 miles urban route and the many companies like Google, Uber contributing to developing it for commercial use. [8] This period these advance features like sensory issue, collision warnings \& avoidance safety are still under observation.

$₫ 1920 s \square 1930 s \square 1950 \square 1960 \square 1980 \square 1990 \square 2000 \square 2013$

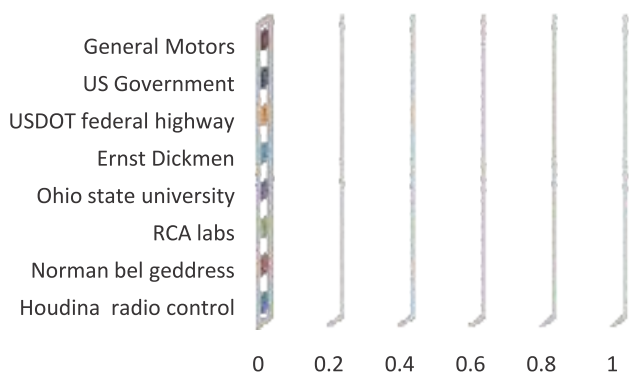

Fig 1: History of automated driving system

\section{SCOPE}

Basically paper is assists those who are less aware with this theme of automation, This paper is about the automated vehicles how it can work and what is the impact of it on different factors like safety issues time issue, how to avoid from collision and what the steps needs to be taken for detection of collision. These are all such things discussed here.

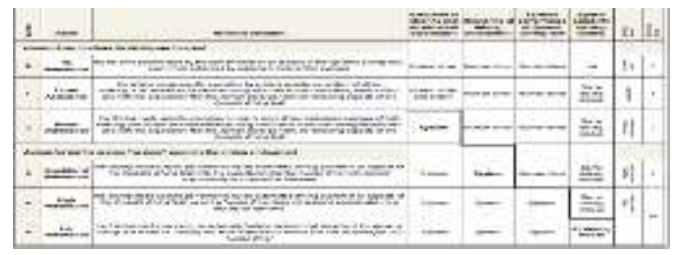

Fig 2: Summary of levels [4]

\section{LEVELS OFAUTOMATION}

\section{A. Level 0(NoAutomation)}

This is 0 level automation in which vehicle is dependent on driver .Driver is responsible for all the functions of driving, these includes brakes, steering wheel, gear levels, throttle and motive power. Driver have to perform all the functions of driving there is no automation in level 0 , [1] system is freely and dependent on driver's actions. And driver is totally responsible for safe operations.

\section{B. Level 1(Function specific Automation)}

Driver Assistance this is the level 1 automation and this automation there were the one or more keen functions which is performed by the vehicle independently and overall functions performed by the driver including safe operations which are the most important function[7]

\section{Level 2(Combined function Automation)}

Partial automation in this level of automation at least 2 primary controlled function are under system (Vehicle) like radar cruise control \& automatic lane centering because to gives relief to the driver but in level 2 automation driver should be alert to re-take the control from the vehicle any time if there is a critical situation or may be in danger when the vehicle system is not able to navigate the car.

\section{Level 3(Limited self-driving Automation) \\ Conditional automation this type of an} automation permits the driver to transfer all safety \& critical function of the vehicle under some conditions now the vehicle is responsible for driving and to identify situation which require driver presence. And if the vehicle didn't understand the situation then driver should be alert to take the control from the vehicle to manage the driving in case of danger. But vehicle must be provide warning that allows for a changeover back to no automation otherwise it will be the problem creative.

\section{E. Level 4(High Automation)}

In this automation driving mode specific performance is perform by an automated system ,vehicle is responsible to all of the functions of driving performing all the dynamic driving task if the driver is not respond.[1]

\section{F. Level 5(Full Automation)}

In this automation full time performance of automated driving system to check all the aspects of a dynamic driving, all the check and balance of the roads and all environmental condition that a human driver can do. [7] 


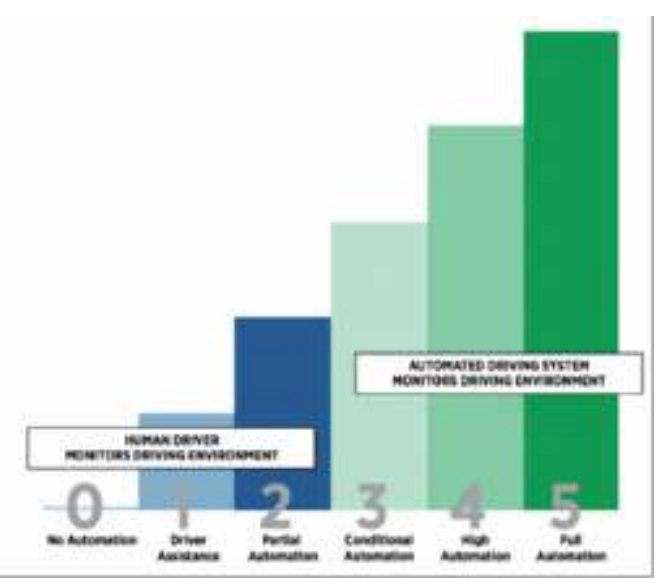

Fig 3: Levels of automation [7]

\section{A UTONOMOUS VEHICLE OPERATIONAL MODELS}

\section{A. Personal autonomous vehicle[4]}

This type of a vehicle is used for those who travels a lot they need more times a ride in a day they don't want to leak their privacy, so this vehicle containing high availability without any delay also very high convenience. But this type of vehicle having high cost, mostly are unable to pay such a huge cost for the ride, that's why they don't prefer it.

\section{B. Shard Autonomous vehicle[4]}

This type of vehicle is for those who can't pay such a huge amount, they are agree to share the vehicle with anyone. User can choose vehicle of their own choice from the availability but user have to wait for these vehicles because of the limited service which is used by many users.

\section{Shared autonomous rides [4]}

This type of vehicle is for lower income users which shares among many other users these are the self-driving vans containing least comfort, least convenience but these vehicles have lower cost.

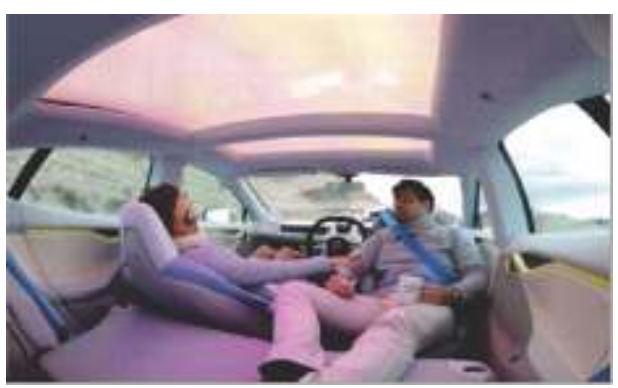

Fig 4: Automated driving model [8]

\section{I N F R A S T R U C T U R E O F} AUTOMATION

\section{A. Vehicle Automation}

Development in crash control directed to vehicle design which are more saver from Collision. But the negligence of the driver causes rear end collision because the driver not fully pay attention to the driving task, approximately. [5] 1.8 million accidents happened only because of the driver in attention. So this type of collisions can be avoided by collision warning system.

\section{B. Collision warning system}

Collision warning system is used to overcome from collision by warning driver. Driver should attentive and communicate the situation for a reliable ride. Statistical data shows that the major accidents can happen due to the poor understanding or judging the dangerous situation of the driver. But we can overcome it with some precautions by warn the driver about collision approximately [5]60-90\% collision can be avoided with 1 second warning time. Regulatory state agencies and car companies try to control it some are the challenging issues that we are facing.

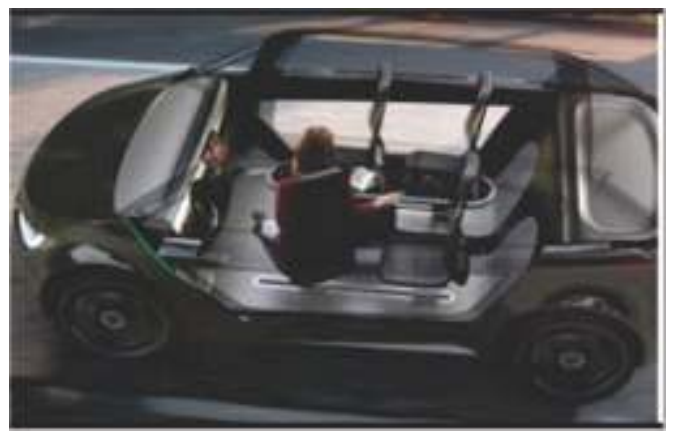

Fig 5: Automated vehicle [4]

\section{Human factors issues}

Timely and accurately determination is a big issue driver should be alert for safety. Driver is responsible for supervision of the automated task. Normally system gives relief to the driver from physical task but human always alert to retake control. [5] Driver psychology and behavior is needy for the evaluation effect of different design.

\section{Liability issues}

The state of being legally responsible for safety like giving warning to driver about 
mishappeing,recording the performance of the system, buying liability insurance after purchasing. Cooperating with federal agencies in implementation of driver warning system so legal person who is doing such kinds of a task should be alert to warning [5].

\section{Control issues}

The agencies who is responsible to control all the issues like liability and human factor issue if they are not work properly so agencies should control it.

\section{Control structure of automation}

There are the 2 types of control structure I automated system.

\section{Lowlevel controller}

[5]In automated system the function of low level controller is to control the engine, brakes, and steering in this way the driver feels comfortable while driving.

\section{Higher level controller}

In automated system the task of higher level controller is to determine the motion of low level controller with proper understanding of the vehicle. Higher level controller analyses the acceleration which decrease and increase the speed of velocity of preferred value. Input will be taken from the driver then the vehicle sensor sends command like brake. Weigh-edge of the vehicle relay on different scenarios [5]. Outstanding assessment of Mass and road expands the higher level controller.

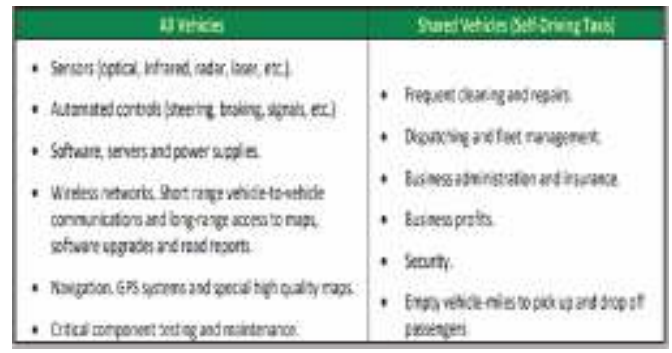

Fig 5: Required equipment [5]

\section{DRIVER VEHICLE INTERACTION}

Driver vehicle interaction is most important factor of an automated system because if they were not properly interact with each other then most of the accidents will happen. Driver should fully alert in driving when the control is in systems hand and must check out the situations in which system can't perform controlling function then driver is able to retake the control of driving from the system.

Drivers in (lane departure warning system \& forward collision warning) during normal driving engage themselves in visual secondary task they are attentive to retake the control to avoid accidents [3]. Some instruction have to follow to enhance the Driver Vehicle Interaction...

A. Involve driver in driving task when system is involve.[9]

B. Encourage pictorial attention to forward roadway.

C. Driver should be in lane to avoid overburden an inattention.

D. Active alerts for system letdown and limitation.

E. System will provide timely and explicit feedback about future behavior of a representative.

F. User will have a conceptual model of how system behaves in precise situation.

G. System schedules should be consistent.[3]

\section{BENEFITS OF AN AUTOMATED SYSTEM}

A. Manufactures produces seats which turns into bed.[4]

B. Self-driving cars permits travelers to work \& rest.

C. Providing mobility for non-drivers who can't drive.[4]

D. By self-driving stress is reduces.

E. Improves productivity.

F. Increase economic productivity.

G. Improves education \& employment opportunities.[4]

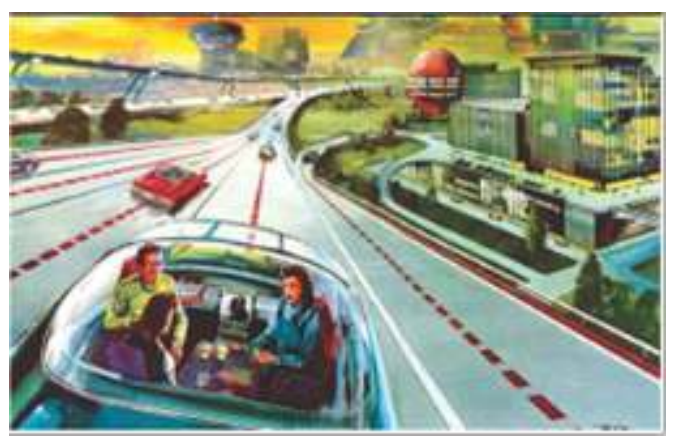

Fig 7: Work and rest [4] 


\section{WEAKNESSES OF AUTOMATED SYSTEM}

\section{OLDER DRIVER ISSUES}

A. Physical aspects [2]

1. $90 \%$ drivers relay on private cars

2. Slow response time.

3. Vision problems.

4. Depth perception changes.

5. Hearing problem.

6. Decrease ability to focus.

7. Feeling of nervousness.

8. Medical issues.

B. Social Aspects[2]

1. Not an idea about to change a tire.

2. Lack of mobility.

C. Familiarizes new stress and discomfort mentally dissatisfaction.

D. Destruction cost.

E. Vans having interior vandalism stainless steel.[4]

F. While ride sharing in the forms of vans reduces security.

G. Reduces travel speed and trustworthiness in ride sharing [8].

H. Unreliable in urban traffic or unable to control in heavy rain and snow.[4]

I. Supplementary passenger's interruption like children, older or disable who require extra time to pick and drop.

J. Autonomous vehicle require extra cost to operate and repair hundreds of dollars annual fee increase their cost.

K. Cruise control, lane centering cameras, fee is $\$ 5000$ approx. and navigation, security is $\$ 200-600$ in a year.[4]

L. Self-driving car possibility is closer term but the capability is unclear.

M. Automated vehicle improves security but not in large scale.

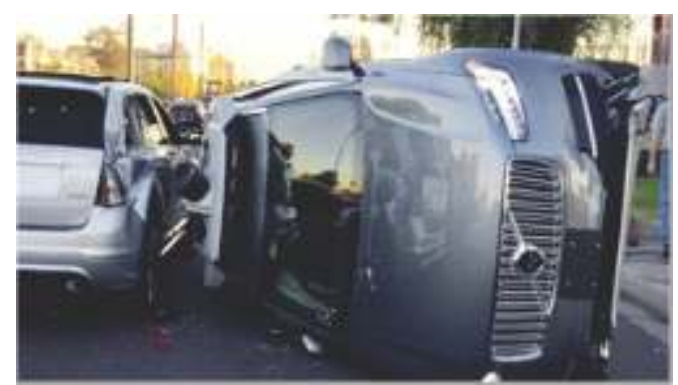

Fig 8: Car crash in automated system [8]

\section{CONCLUSION}

In this paper we have reviewed the development in automated driving system which is the most important trend in today's research. The focus of the paper is to clarify the concept of automated system to the user in this way they can understand the working of automated system. Different factors are discussed in this paper, working of automated system and its implementation models to ensure time save, in reaching destination. It provides better interaction level between driver and system in such a way they can reduce collision by avoidance or giving warnings to the driver in different formats for safety, because safety is a major issue in automated driving different issues are raised in safety like safety on a large scale but proper detection of collision and some guidelines we can overcome it in future.

\section{REFERENCES}

[1] Administration, 7. N. (2013). Autonomous Vehicles.

[2] administration, N. h. (2014). Human Factors Evaluation of Level 2. 2-3.

[3] Cervantes, M. S. (2011). Issues of Control with Older Drivers and Future.

[4] CPB. (2015). Automated and autonoumous driving. International transport forum, 5 .

[5] CPB. (n.d.). Automated and autonoums driving. International transport forum.

[6] E. Frink, D. F. (2016). Invisible Leash: Object-Following Robot". Mobile Robotics \& Intelligent Systems, .

[7] Institute, V. T. (2018). Autonomous Vehicle Implementation Predictions. 3 7.

[8] K. R. Memon, S. M. (2016). Real time Implementation of Path planning Algorithm with Obstacle Avoidance for Autonomous Vehicle. InternationalConference on Computing for Sustainable Global Development".

[9] M. Weber. (2014). A History of Autonomous Vehicles. 
[10] Mrs. Smita Desai, M. S. (2017). SMART VEHICLE AUTOMATION. International Journal of Computer Science and Mobile Computing, 1-5.

[11] National highway traffic safely administrtion. (2013). Autonoumus vehicle.

[12] Rau, P. (2015). "Target Crash Population of Automated Vehicles. (ESV.

[13] Ruth Madigan*, T. L. (2018). The effect of varying levels of vehicle automation on drivers' lane changing. PLOS, 1-2.
[14] shah, w. (2016). Self-driving and driver relaxing vehicle. Rawalpindi, Pakistan: IEEE.

[15] States, U. ( (2 $\left.0 \begin{array}{lll}0 & 1 & 2\end{array}\right)$. D RIVER PROFILING . Patent Application Publication, $1-2$.

[16] wikipediq/encyclopedia. (2017). history of automated system. 